\title{
Novel Reagents for the Spectrophotometric Determination of Isoniazid
}

\author{
Divya N. Shetty, Badiadka Narayana, and Seranthimata Samshuddin
}

Department of Chemistry, Mangalore University, Karnataka, Mangalagangothri 574 199, India

Correspondence should be addressed to Badiadka Narayana, nbadiadka@gmail.com

Received 11 April 2012; Accepted 10 May 2012

Academic Editors: A. A. Ensafi, D. V. Konarev, and N. Zanatta

Copyright ( $) 2012$ Divya N. Shetty et al. This is an open access article distributed under the Creative Commons Attribution License, which permits unrestricted use, distribution, and reproduction in any medium, provided the original work is properly cited.

\begin{abstract}
Isoniazid is an antitubercular drug, widely used for tuberculosis. Owing to its importance in therapeutics, the present study aims to develop simple method for the spectrophotometric determination of isoniazid (INH). Two novel reagents, epichlorohydrine $(\mathrm{ECH})$ and 4-hydroxyphenaylchloride (HPC) are used for the spectrophotometric determination of INH. Based on the nucleophilic substitution reactions of INH with EPI \& HPC in basic medium, rapid, simple, inexpensive, precise, and accurate visible spectrophotometric method is proposed for the determination of INH in bulk drug and in formulations. Method involves the reaction of INH with EPI and HPC in basic medium to form yellow-colored chromogen, measuring the absorbances at 405 and $402 \mathrm{~nm}$ for INH-EPI \& INH-HPC, respectively. The optimum experimental conditions have been studied. The absorbance was found to increase linearly with the concentration of the drug and formed the basis for quantification. The calibration graphs were linear from $2.00-22.00 \mu \mathrm{g} \mathrm{mL}^{-1}$ and $20.00-120.00 \mu \mathrm{g} \mathrm{mL}^{-1}$ for INH-EPI \& INH-HPC, respectively. The apparent molar absorptivity and Sandell's sensitivity are calculated to be $0.51 \times 10^{4} \& 0.10 \times 10^{4} \mathrm{~L} \mathrm{~mol}^{-1} \mathrm{~cm}^{-1}$ and $0.027 \& 0.134 \mu \mathrm{g} \mathrm{cm}{ }^{-2}$ for INHEPI \& INH-HPC, respectively. The procedure is used to determine INH in pharmaceutical products. The associated pharmaceutical materials do not interfere in the measurements.
\end{abstract}

\section{Introduction}

The enhanced prevalence of infectious diseases threatens world population. Tuberculosis (TB) is characterized as a chronic bacterial infection caused by a germ called Mycobacterium tuberculosis. TB is contagious and spreads through the air when a person with TB of the lungs or throat coughs, sneezes, or talks. Worldwide statistics on tuberculosis surprisingly reveals that, one-third of the world's population, over 2 billion people, carry the bacillus that causes TB and 2 million people die of the disease each year. Tuberculosis is on the increase in recent years, largely owing to HIV infection, immigration, increased trade, and globalization [1].

Among the many drugs discovered for the treatment of $\mathrm{TB}$, isoniazid (INH) is one of the powerful drug candidates. The discovery of INH was based on the nicotinamide activity against tubercle bacilli in the animal model observed by Chorine in 1945 [2] and the reshuffling of chemical groups in the thiosemicarbazone $[3,4]$. INH represented a major milestone in the chemotherapy of TB because it is highly active, inexpensive, and without significant side effects $[5,6]$. INH keeps on to be the cornerstone of all antituberculosis regimens and remains the only agent recommended for tuberculosis chemoprophylaxis in children $[7,8]$.

INH is still designated as an essential antituberculosis agent by the World Health Organization (WHO), and is now largely used together with rifampicin and streptomycin for the chemotherapy of TB. This has prompted many investigators to plan methods for the rapid determination of INH in its pure form as well as in pharmaceutical preparations. There are various analytical procedures for the assay of $\mathrm{INH}$, the most important being titrimetry $[9,10]$, visible spectrophotometry [11-13], polarography [14], coulometry [15], high-performance liquid chromatography [16], and fluorimetry [17] methods. The spectrophotometric methods involve the use of reagents such as chloranil [18], 4-nitrobenzaldehyde, pyridoxal [19], 4dimethylaminobenzaldehyde [20], and so forth. In the 
present work two methods have been developed for the determination of INH using two novel reagents. The methods entail the nucleophilic substitution reactions of INH with epichlorohydrine (EPI) and 4-hydroxyphenacylchloride (HPC).

\section{Experimental}

2.1. Apparatus. A UV-Visible spectrophotometer (SHIMADZU, Model no.: UV-2550) with $1 \mathrm{~cm}$ matched quartz cells was used for the absorbance measurements.

2.2. Reagents and Solutions. All the reagents used were of analytical reagent grade. The solutions of EPI in ethanol $(10 \%)$, HPC in ethanol $(0.2 \%)$, and $\mathrm{NaOH}(1 \mathrm{M})$ were prepared. A $1000 \mu \mathrm{g} \mathrm{mL}^{-1}$ of INH solution was prepared using ethanol.

\subsection{Procedures}

2.3.1. Using EPI as Reagent. Aliquots containing 2.00$22.00 \mu \mathrm{g} \mathrm{mL}^{-1}$ of INH were transferred into series of $10 \mathrm{~mL}$ calibrated flasks. To this, $1 \mathrm{~mL}$ of EPI (10\%) was added followed by $1 \mathrm{~mL}$ of $\mathrm{NaOH}(0.25 \mathrm{M})$ and heated for $5 \mathrm{~min}$. The reaction mixture was cooled and made up to $10 \mathrm{~mL}$ with distilled water. The absorbance of each was measured at $405 \mathrm{~nm}$.

2.3.2. Using HPC as Reagent. Aliquots containing 20.00$120.00 \mu \mathrm{g} \mathrm{mL}^{-1}$ of INH were transferred into series of $10 \mathrm{~mL}$ calibrated flasks. To this, $1 \mathrm{~mL}$ of HPC $(0.2 \%)$ was added followed by $0.5 \mathrm{~mL}$ of $\mathrm{NaOH}(1 \mathrm{M})$ and heated for $5 \mathrm{~min}$. The reaction mixture was cooled and made up to $10 \mathrm{~mL}$ with distilled water. The absorbance of each was measured at $402 \mathrm{~nm}$.

2.3.3. Assay of Formulations. The proposed method has been applied successfully for the determination of INH in some pharmaceutical formulations. Commercial INH tablets (Solonex and Isokin) were analyzed using the developed method. To minimize a possible variation in the composition of the tablets, the mixed contents of 20 tablets were weighed and ground, then the powder equivalent to $300 \mathrm{mg}$ INH was dissolved in water by stirring for $10 \mathrm{~min}$ and filtered through Whatman No. 41 filter paper. Solutions of working concentration were prepared by proper dilution of this stock solution with water and followed the above procedures for the analysis.

\section{Results and Discussion}

\subsection{Absorption Spectra and Optimization of Reagent Concentrations}

3.1.1. Using EPI as Reagent. The proposed method is based on the nucleophilic substitution reaction of EPI in presence of $\mathrm{NaOH}$ to form yellow-colored chromogen (Scheme 1), the absorbances of which can be measured at $405 \mathrm{~nm}$ (Figure 1).

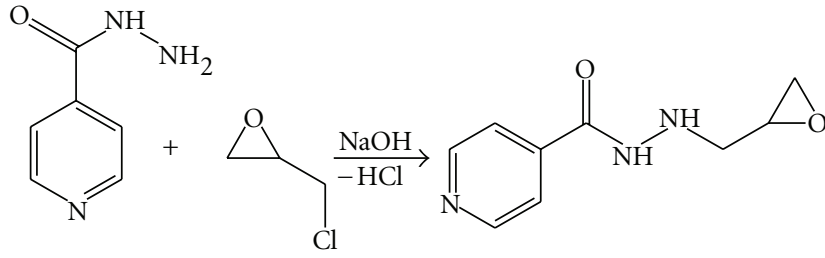

Scheme 1: Reaction of INH with ECH.

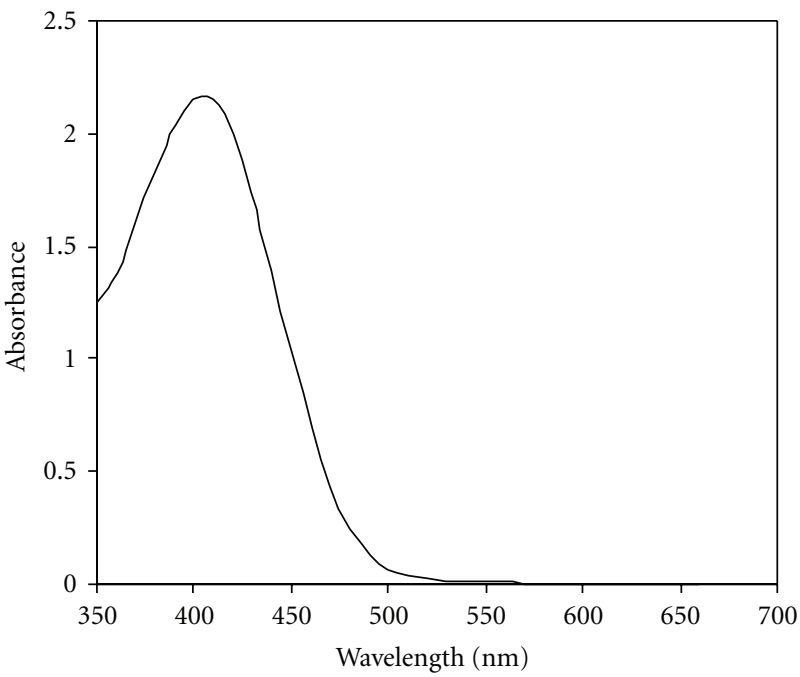

Figure 1: Absorption spectrum of INH-EPI system.

Conditions for the assay procedures have been established by studying the reactions as a function of heating time, concentration of reagents, solution stability, and the stability of the colored species.

Preliminary experiments are carried out to fix the initial concentration of the reagents. The influence of the volume of $0.25 \mathrm{M} \mathrm{NaOH}$ on the formation of yellow color is studied. This is performed by keeping other parameters constant and taking different volumes of $(0.1-5.0 \mathrm{~mL})$ of $0.25 \mathrm{M} \mathrm{NaOH}$. The maximum absorbance is obtained with $1 \mathrm{~mL}$ of $\mathrm{NaOH}$. Above this volume absorbance remains constant. Therefore, this volume is used for all the absorbance measurements. To investigate the optimum heating time for color development, the content of the mixture is heated on water bath at $60^{\circ} \mathrm{C}$ for $5-10 \mathrm{~min}$. The maximum intensity of color is obtained at $5 \mathrm{~min}$ of heating at $60^{\circ} \mathrm{C}$ and remains constant. To study the effect of concentration of EPI, different volumes of $10 \%$ $\mathrm{ECH}$ are tested. It is found that $1 \mathrm{~mL}$ of EPI is sufficient for very good color intensity.

3.1.2. Using HPC as Reagent. The method is based on the nucleophilic substitution reaction of HPC with isoniazid in presence of $\mathrm{NaOH}$ (Scheme 2). The absorbance of the product formed is measured at $402 \mathrm{~nm}$ (Figure 2).

Preliminary experiments were carried out to fix the initial concentration of the reagents. The influence of the volume of $1 \mathrm{M} \mathrm{NaOH}$ on the formation of yellow color is studied. This is performed by keeping other parameters constant 


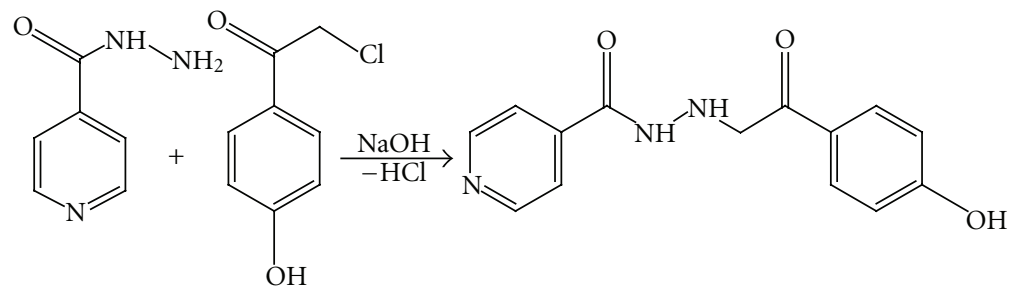

SCHEME 2: Reaction of INH with HPC.

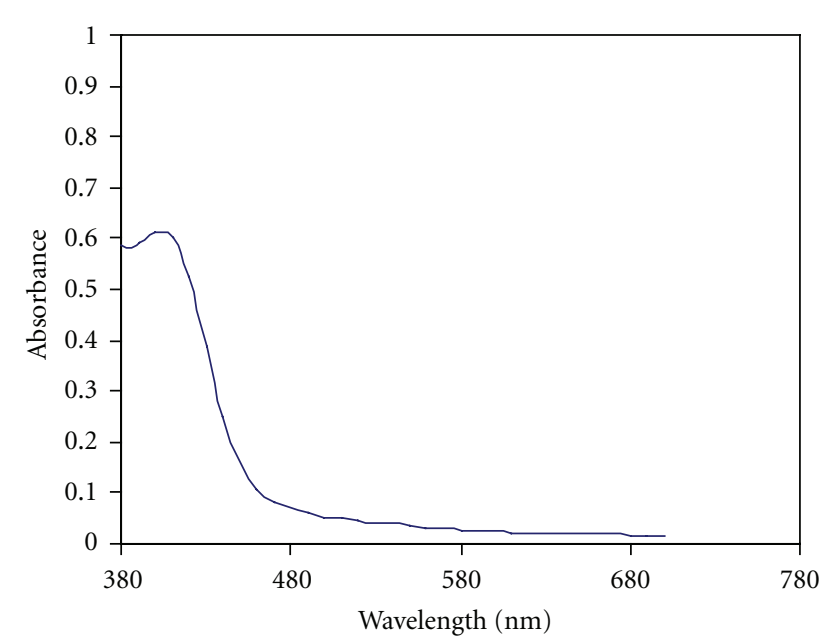

FIGURE 2: Absorption spectrum of INH-HPC system.

and different volumes of $(0.1-5.0 \mathrm{~mL})$ of $1 \mathrm{M} \mathrm{NaOH}$. The maximum absorbance is obtained with $1 \mathrm{~mL}$ of $\mathrm{NaOH}$. Above this volume absorbance remains constant. Therefore this volume is used for all the absorbance measurements. To investigate the optimum heating time for color development, the content of the mixture is heated on a water bath at $60^{\circ} \mathrm{C}$ for 5-30 min. The maximum intensity of color is obtained at $15 \mathrm{~min}$ of heating and remains constant. To study the effect of concentration of HPC, different volumes of $0.2 \%$ HPC are tested. It is found that $1 \mathrm{~mL}$ of HPC is sufficient for very good color intensity.

3.2. Analytical Data. The linearity between two parameters is apparent from the correlation coefficient obtained by the method of least squares. The optical characteristics such as absorption $\lambda_{\max }$, Beer's law limits, molar absorptivity, Sandell's sensitivity, detection limit and quantification limit, are calculated. The regression analysis of the Beer's law plots at their respective $\lambda_{\max }$ values revealed a good correlation. Graphs of absorbance v/s concentration show negligible intercept and are described by the regression equation $Y=$ $a+b X$. Where $Y$ is the absorbance, $b$ is the slope, $a$ is the intercept, and $X$ is the concentration of the drug in $\mu \mathrm{g} \mathrm{mL} L^{-1}$ obtained by the least-squares method (Table 1).

3.3. Method Validation. Validation of an analytical procedure is the process by which it is ascertained, by laboratory studies, that the performance characteristics of the procedure
TAble 1: Analytical parameters.

\begin{tabular}{lcc}
\hline & EPI & HPC \\
\hline$\lambda_{\max } \mathrm{nm}$ & 405 & 402 \\
Beer's law limit $\left(\mu \mathrm{g} \mathrm{mL}^{-1}\right)$ & $2.00-22.00$ & $20.00-120.00$ \\
Molar absorptivity $\left(\mathrm{L} \mathrm{mol}^{-1} \mathrm{~cm}^{-1}\right)$ & $0.51 \times 10^{4}$ & $0.10 \times 10^{4}$ \\
Sandell's sensitivity $\left(\mu \mathrm{g} \mathrm{cm}^{-2}\right)$ & 0.027 & 0.134 \\
Regression equation* & $Y=a+b X$ & $Y=a+b X$ \\
Slope $(b)$ & 0.0336 & 0.0064 \\
Intercept $(a)$ & 0.022 & 0.018 \\
Correlation coefficient $(r)$ & 0.9910 & 0.9979 \\
Limit of Detection** $\left(\mu \mathrm{g} \mathrm{mL}^{-1}\right)$ & 1.500 & 5.150 \\
Limit of Quantitation** $\left(\mu \mathrm{g} \mathrm{mL}^{-1}\right)$ & 4.545 & 15.620 \\
\hline
\end{tabular}

${ }^{*} Y$ is the absorbance and $X$ is the concentration in $\mu \mathrm{g} \mathrm{mL}^{-1}$.

${ }^{* *}$ Calculated using ICH guidelines.

meet the conditions for its proposed use. All analytical methods planned to be used for analyzing any experimental samples will need to be authenticated. The accuracy of the method was established by analyzing the pure drugs at diverse levels within working limits and the precision is ascertained by calculating the relative standard deviation of replicate determinations on the same solution containing the drugs at different levels and are presented in Tables 2(a) and 2(b). The relative error and relative standard deviation indicate the high accuracy and precision for the method. In order to check the validity of the proposed method, INH is determined in some commercial formulations. From the results it is clear that there is close agreement between the results obtained by the proposed method and the label claim.

3.4. Interference Study. The specificity of an analytical method may be defined as the ability to clearly determine the analyte in the presence of additional components such as impurities, degradation products, and matrix. The specificity in the current case is evaluated by preparing the analytical placebo and it is confirmed that the change in absorbance with respect to the reagent blank is caused only by the analyte. A solution of the analytical placebo (containing all the tablet excipients except INH) is prepared according to the sample preparation procedure and subjected to analysis using the procedures described earlier. The absorbance measured is nearly the same as that of the reagent blank. To identify the interference by these excipients, a synthetic mixture of inactive ingredients (placebo) including INH with the following composition: INH (10 mg), talc (20 mg), starch 
TABLE 2: (a) Evaluation of accuracy and precision (using ECH as reagent). (b) Evaluation of accuracy and precision (using HPC as reagent).

(a)

\begin{tabular}{|c|c|c|c|c|}
\hline Amount taken $\left(\mu \mathrm{g} \mathrm{mL}^{-1}\right)$ & Amount found ${ }^{*}\left(\mu \mathrm{g} \mathrm{mL}^{-1}\right)$ & RE (\%) & $\mathrm{SD}\left(\mu \mathrm{g} \mathrm{mL}^{-1}\right)$ & RSD (\%) \\
\hline 2.00 & 1.98 & 1.00 & 0.015 & 0.79 \\
\hline 4.00 & 3.97 & 0.75 & 0.0207 & 0.52 \\
\hline 6.00 & 5.96 & 0.66 & 0.0239 & 0.4 \\
\hline 8.00 & 7.97 & 0.37 & 0.0259 & 0.32 \\
\hline 10.00 & 9.96 & 0.4 & 0.0270 & 0.27 \\
\hline 12.00 & 11.95 & 0.41 & 0.0404 & 0.33 \\
\hline
\end{tabular}

${ }^{*}$ Mean of five determinations.

(b)

\begin{tabular}{lcccc}
\hline Amount taken $\left(\mu \mathrm{g} \mathrm{mL}^{-1}\right)$ & Amount found $\left.(\mu \mathrm{g} \mathrm{mL})^{-1}\right)$ & $\mathrm{RE}(\%)$ & $\left.\mathrm{SD}(\mu \mathrm{g} \mathrm{mL})^{-1}\right)$ & 0.09 \\
\hline 20.00 & 19.99 & 0.05 & 0.06 & 0.45 \\
40.00 & 40.03 & -0.08 & 0.12 & 0.14 \\
60.00 & 59.96 & 0.06 & 0.08 & 0.10 \\
80.00 & 79.93 & 0.08 & 0.08 \\
\hline
\end{tabular}

${ }^{*}$ Mean of five determinations.

RE: relative error; SD: standard deviation; RSD: relative standard deviation.

(40 mg), glucose (50 mg), and lactose (40 mg) is prepared. The entire mixture is transferred into a $100 \mathrm{~mL}$ calibrated flask, the content shaken for $20 \mathrm{~min}$, volume diluted to the mark with distilled water, mixed well, and filtered. The filtrate after suitable dilution is analyzed by proposed methods. The difference between the measured absorbance of the above extract and that of a standard INH solution of the same concentration is less than $2 \%$ indicating the absence of interference by the excipients.

3.5. Applications. The proposed method has been applied to the determination of INH in pure and dosage form. The results are compared statistically with those of the tabulated value at $95 \%$ confidence level. The calculated student's $t$ test (Table 3 ) does not exceed the tabulated value, indicating that there is no significant difference between the proposed method and the tabulated value. The described method has been extensively validated in terms of specificity, linearity, accuracy and precision, and system suitability.

\section{Conclusions}

The new approach of utilizing epichlorohydrine and 4hydroxyphenayl chloride as reagents in spectrophotometry is the first of such reports. The method makes use of very easily available and cheaper reagents which demonstrates its cost-effectiveness. Compared to many existing instrumental methods for INH, the proposed spectrophotometric method has two additional advantages of simplicity of operations and low-cost instrument. These advantageous features advocate its use in quality control laboratories for routine use.
TABLE 3: Results of assay of formulations.

\begin{tabular}{lcc}
\hline Brand name & ${ }^{a}$ Isokin & ${ }^{\mathrm{b}}$ Solonex \\
\hline Labeled amount $(\mathrm{mg})$ & 300 & 300 \\
\hline (1) Using ECH & & \\
(i) Amount found ${ }^{*}(\mathrm{mg})$ & 299.5 & 299.0 \\
(ii) \% Label claim \pm SD & $99.83 \pm 0.010$ & $99.66 \pm 0.018$ \\
(iii) $t$-test & 2.23 & 2.48 \\
\hline
\end{tabular}

(2) Using HPC

\begin{tabular}{|c|c|c|}
\hline (i) Amount found* (mg) & 299.70 & 299.81 \\
\hline (ii) $\%$ Label claim $\pm \mathrm{SD}$ & $99.90 \pm 0.08$ & $99.93 \pm 0.06$ \\
\hline (iii) $t$-test & 1.67 & 1.62 \\
\hline
\end{tabular}

${ }^{*}$ Mean value of five determinations.

apfizer Ltd., India.

${ }^{b}$ Macleods Pharmaceuticals Ltd.

Calculated Student's $t$-value at $95 \%$ confidence level is 2.77 .

\section{Acknowledgments}

B. Narayana thanks the UGC for financial assistance through SAP and BSR one-time grant for the purchase of chemicals. Divya N. Shetty thanks the UGC-RFSMS scheme (under SAP-Phase1) for providing financial help for the research work.

\section{References}

[1] K. C. Smith, L. Armitige, and A. Wanger, "A review of tubercolosis: reflections on the past, present and future of a global epidemic disease," Expert Review of Anti-Infective Therapy, vol. 1, no. 3, pp. 483-491, 2003.

[2] V. Chorine, "Médecine expérimentale-Action de l'amide nicotinique sur les bacilles du genre mycobacterium," Comptes 
Rendu Hebdomadaires des Séances de l'Académie des Sciences, vol. 220, no. 4, pp. 150-151, 1945.

[3] J. Bernstein, W. A. Lott, B. A. Steinberg, and H. L. Yale, "Chemotherapy of experimental tuberculosis. V. Isonicotinic acid hydrazide (Nydrazid) and related compounds," The American Review of Tuberculosis, vol. 65, no. 4, pp. 357-364, 1952.

[4] H. A. Offe, W. Siefken, and G. Domagk, "The tuberculostatic activity of hydrazine derivatives from pyridine carboxylic acids and carbonyl compounds," Zeitschrift für Naturforschung B, vol. 7, pp. 462-468, 1952.

[5] D. L. Griffiths, A. G. Quinlan, and H. J. Richards, "Isoniazid in treatment of bone and joint tuberculosis: a review of 20 cases," The British Medical Journal, vol. 1, no. 4875, pp. 1355-1359, 1954.

[6] Y. Zhang, "The magic bullets and tuberculosis drug targets," Annual Review of Pharmacology and Toxicology, vol. 45, pp. 529-564, 2005.

[7] H. H. Fox, "The chemical approach to the control of tuberculosis," Science, vol. 116, no. 3006, pp. 129-134, 1952.

[8] D. Jenkins and F. F. Davidson, "Isoniazid chemoprophylaxis of tuberculosis," California medicine, vol. 116, no. 4, pp. 1-5, 1972.

[9] A. M. El-Brashy and S. M. El-Ashry, "Colorimetric and titrimetric assay of isoniazid," Journal of Pharmaceutical and Biomedical Analysis, vol. 10, no. 6, pp. 421-426, 1992.

[10] C. J. Shishoo and M. B. Devani, "Nonaqueous titrimetric determination of isoniazid in presence of excess of sodium p-aminosalicylate in dosage forms," Journal of Pharmaceutical Sciences, vol. 59, no. 1, pp. 92-93, 1970.

[11] A. Safavi, M. A. Karimi, M. R. H. Nezhad, R. Kamali, and N. Saghir, "Sensitive indirect spectrophotometric determination of isoniazid," Spectrochimica Acta-Part A, vol. 60, no. 4, pp. 765-769, 2004.

[12] M. E. El-Kommos and A. S. Yanni, "Spectrophotometric determination of isoniazid using 6,7-dichloroquinoline-5,8-dione," Analyst, vol. 113, no. 7, pp. 1091-1095, 1988.

[13] P. Nagaraja, K. Sunitha, R. Vasantha, and H. Yathirajan, "Novel method for the spectrophotometric determination of isoniazid and ritodrine hydrochloride," Turkish Journal of Chemistry, vol. 26, no. 5, pp. 743-750, 2002.

[14] J. J. Vallon, A. Badinand, and C. Bichon, "Determination of isoniazid, $\mathrm{N}$ acetylisoniazid and isonicotinic acid by polarography with superimposed sinusoidal tension," Analytica Chimica Acta, vol. 78, no. 1, pp. 93-98, 1975.

[15] V. J. Jennings, A. Dodson, and A. Harrison, "Coulometric microtitration of arsenic(III) and isoniazid using a vitreous carbon generating electrode," Analyst, vol. 99, no. 1177, pp. 145-148, 1974.

[16] J. T. Stewart, I. L. Honigberg, and J. P. Brant, "Liquid chromatography in pharmaceutical analysis. V. Determination of an isoniazid pyridoxine hydrochloride mixture," Journal of Pharmaceutical Sciences, vol. 65, no. 10, pp. 1536-1539, 1976.

[17] J. Bartos, "Elements of functional organic fluorometry. VII. Fluorometry of pyridine derivatives," Annales Pharmaceutiques Francaises, vol. 29, no. 1, pp. 71-73, 1971.

[18] S. T. Sulaiman and D. Amin, "Spectroscopic studies of isonicotinoyl-, nicotinoyl-, and piconoylhydrazines with chloranil," Microchemical Journal, vol. 28, no. 3, pp. 328-330, 1983.

[19] P. R. Shah and R. R. Raje, "Hydrazones of isoniazid for colorimetric analysis," Journal of Pharmaceutical Sciences, vol. 66, no. 2, pp. 291-292, 1977.
[20] N. F. Poole and A. E. Meyer, "Comparison of new chemical method of determining isonicotinoyl hydrazide in serum with microbiological assay," Proceedings of the Society for Experimental Biology and Medicine, vol. 98, no. 2, pp. 375-377, 1958. 


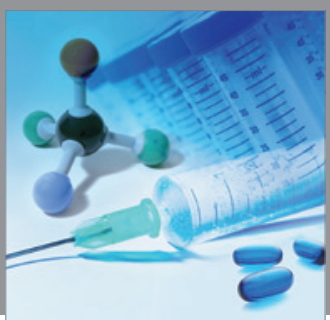

International Journal of

Medicinal Chemistry

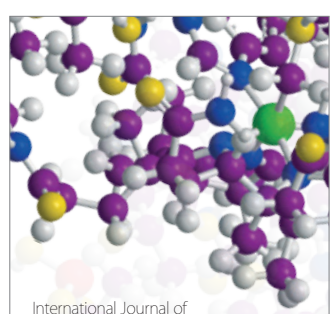

Carbohydrate Chemistry

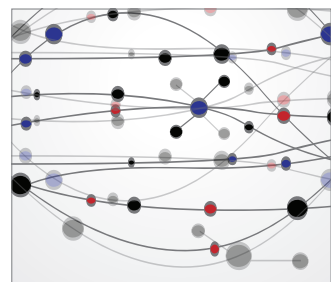

The Scientific World Journal
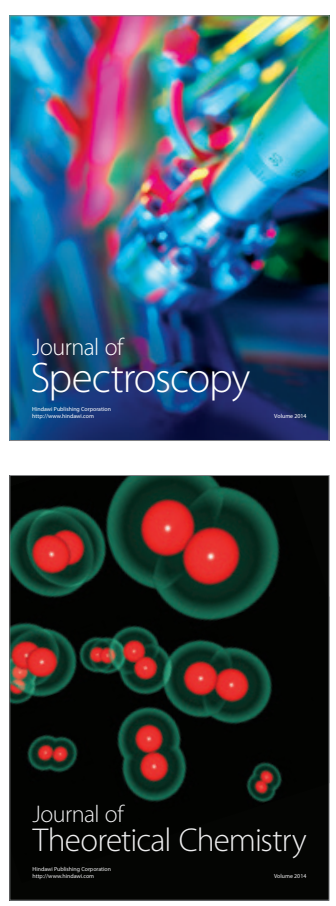
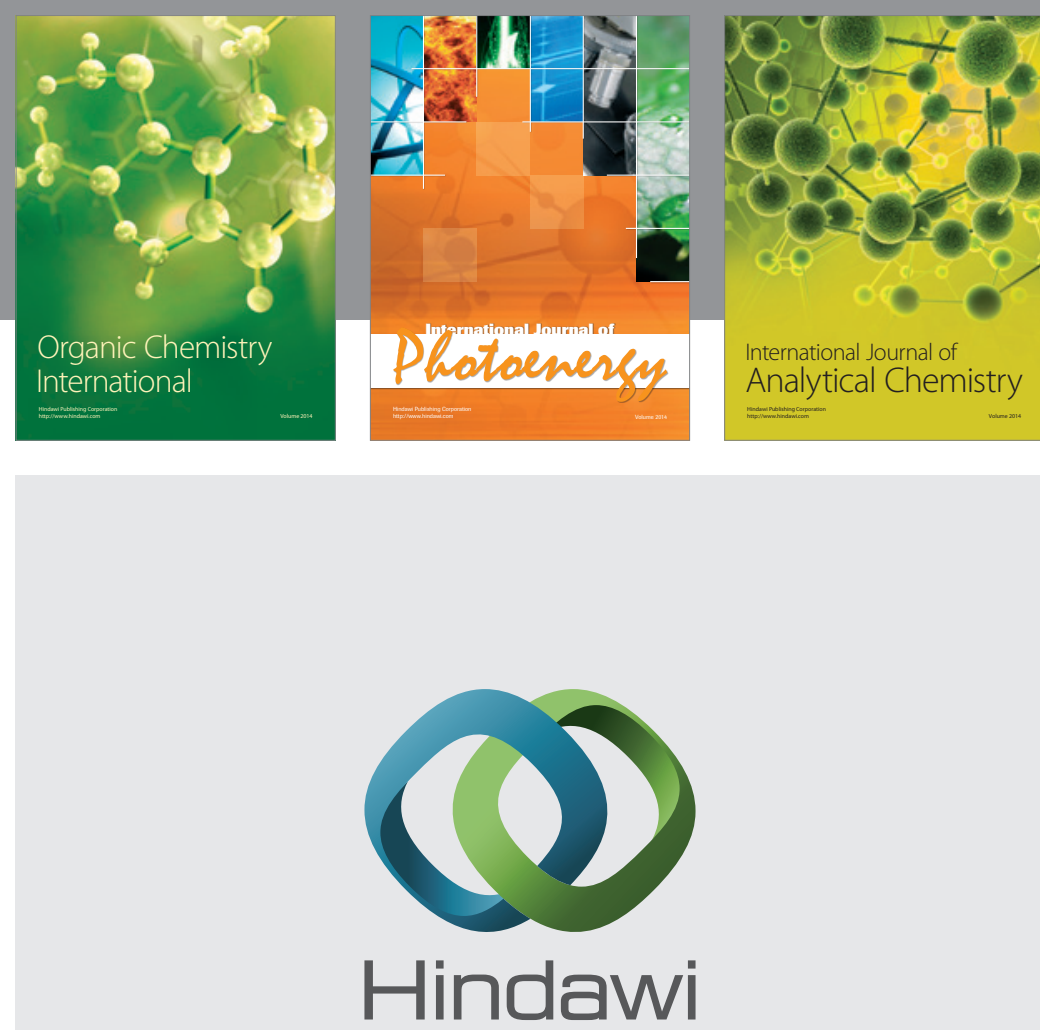

Submit your manuscripts at

http://www.hindawi.com
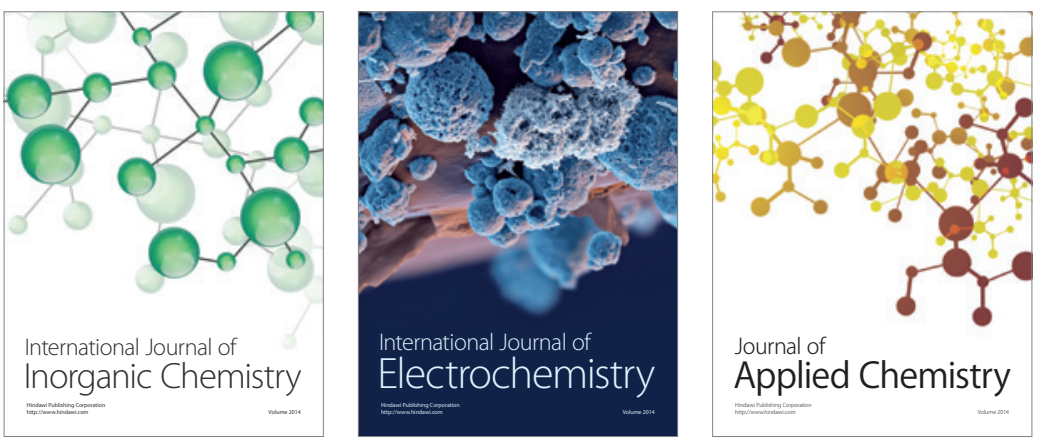

Journal of

Applied Chemistry
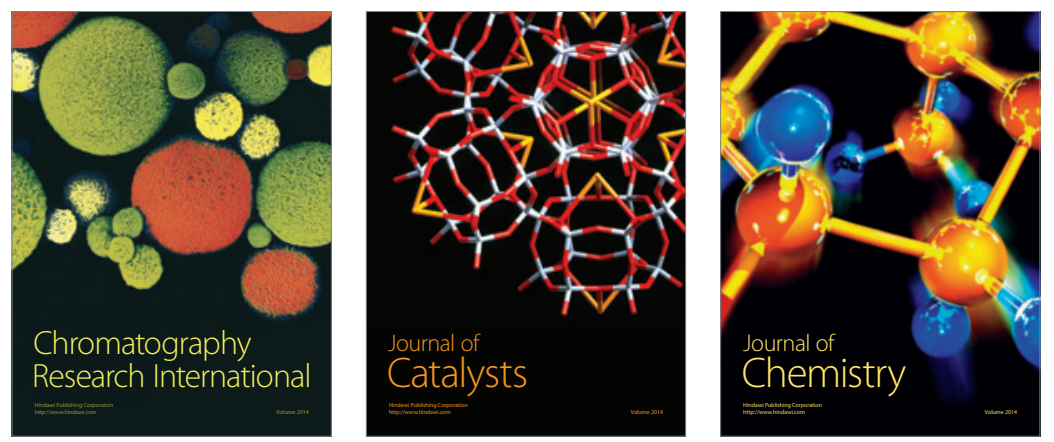
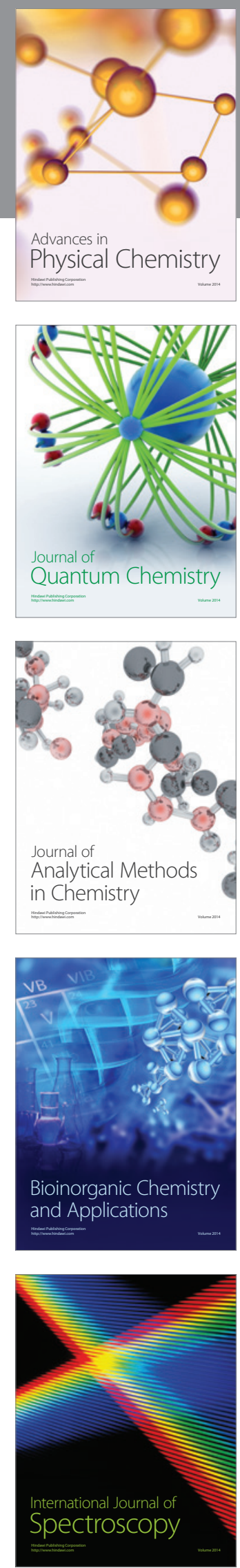